\title{
Fatty Acid Composition of Backfat, Intermuscular, Kidney Pelvis and Heart Fat and Tail Fat of Angus Cross Steers Finished on Grass or High Grain Diets
}

\author{
Gabriela Acetoze ${ }^{1}$ \& Heidi A. Rossow ${ }^{2}$ \\ ${ }^{1}$ Department of Animal Science, University of California, Davis, 1 Shields Ave, Davis, CA 95616, USA \\ ${ }^{2}$ Veterinary Medicine Teaching and Research Center, University of California-Davis, 18830 Road 112, Tulare, \\ CA 93274, USA \\ Correspondence: Heidi A. Rossow, Veterinary Medicine Teaching and Research Center, University of \\ California-Davis, 18830 Road 112, Tulare, CA 93274, USA. Tel: 559-688-1731 × 230. E-mail: \\ Heidi.Rossow@gmail.com
}

Received: December 13, 2013 Accepted: January 5, 2014 Online Published: January 8, 2014

doi:10.5539/jfr.v3n2p9

URL: http://dx.doi.org/10.5539/jfr.v3n2p9

\begin{abstract}
Fatty acid profiles of backfat (BF), intermuscular fat (IMF), kidney pelvic heart (KPH) fat and tail fat (TF) depots from 15-mo old Angus cross steers finished on grass (GS; $n=18$ ) were compared to those finished on a grain diet $(\mathrm{GN} ; \mathrm{n}=14)$ to examine how diet and fat depot impacts fatty acid composition. GS steers grazed an average of 10 months (mo) on ryegrass and white clover irrigated pasture and GN finished steers were a corn based finishing diet for 4 mo. Overall, fat from GS steers contained higher percentages of C6:0 (P = 0.008), C12:0 $(\mathrm{P}=0.003), \mathrm{C} 14: 0(\mathrm{P}=0.001), \mathrm{C} 16: 0(\mathrm{P}=0.002), \mathrm{C} 18: 3(\mathrm{P}=0.008), \mathrm{C} 20: 0(\mathrm{P}<0.001), \mathrm{C} 18: 1$ trans9 $(\mathrm{P}$ $=0.004), \mathrm{C} 18: 2$ cis9 cis12 $(\mathrm{P}<0.001)$ and $\mathrm{C} 18: 2$ trans9 trans12 $(\mathrm{P}<0.001)$ than $\mathrm{GN}$ steers. Fat from GN steers contained higher percentages of $\mathrm{C} 18: 0(\mathrm{P}<0.001)$. For both GS and GN steers, C18:0 content was higher in the $\mathrm{KPH}$ and IMF compared to $\mathrm{BF}$ and $\mathrm{TF}(\mathrm{P}=0.015)$ depots and $\mathrm{C} 18: 1$ cis 9 content was lower in $\mathrm{KPH}$ compared to $\mathrm{BF}$ and TF depots $(\mathrm{P}<0.001)$. Therefore, fatty acid composition differs due to diet and differs across depots. Manipulating diets and source of fat (depot) could be used as strategies to modify the fatty acid composition of meat products to increase health benefits to consumers.
\end{abstract}

Keywords: beef cattle diet, fat depot, fatty acid composition

\section{Introduction}

Adipose tissue is not uniform in fatty acid composition across different depots such as backfat (BF), intermuscular fat (IMF), tail fat (TF), and kidney, pelvic and heart fat (KPH; Pethick et al., 2004). This non uniformity has potentially important implications when examining which depots could be incorporated into meat products such as ground beef (Turk \& Smith, 2009). According to Nicklas et al. (2004), the fatty acid composition of ground beef is an extremely important source of fatty acids to America's diet and can change with age, diet and breed of cattle.

Since fatty acid composition is affected by diet, it is important to understand how fatty acid composition changes across different fat depots in steers fed different diets. Depending on which fat depot is sampled, fatty acid composition could be very different. This difference could have important health implications for which fat depot is added to ground beef as fatty acid composition from some fat depots may be healthier. Why fatty acid composition is different among fat depots is still unclear but adipose tissue turnover rates probably play a role in determining fatty acid composition (Frayn et al., 2006).

From previous studies comparing fatty acid composition in grass and grain finished cattle, it is known that the fatty acid composition of grass finished cattle is higher in conjugated linoleic acid (CLA) and omega-3 fatty acids than grain finished cattle (Daley et al., 2010). In ruminant animals, dietary fat is modified by rumen microbes through biohydrogenation which increases saturated fatty acids (SFA) content of adipose tissue. The saturation process can become incomplete when diets high in unsaturated fats are fed or rumen microbial metabolism is compromised. For instance, grasses contain more linolenic acid (C18:3) compared to grains therefore adipose tissue from grass finished steers contain greater concentrations of C18:3 (Leheska et al., 2008). 
Therefore, the goal of this research is to examine how diet affects fatty acid composition by determining if finishing Angus cross steers on grass or high grain diets alters fatty acid composition of BF, IMF, KPH and TF.

\section{Method}

All procedures involving steers were approved by the Animal Care and Use Committee of the University of California, Davis.

\subsection{Animals and Diet}

Third-two Angus cross steers (approximately 15 mo of age) were obtained from a local ranch (Yolo Land and Cattle Company, Yolo County, California, USA). Steers were randomly assigned between two dietary treatments: grain finish (GN) or grass finish (GS). Initially, sixteen steers were transported to the University of California-Davis feedlot, however two of the steers did not adapt to the feedlot diet and were re-allocated to GS treatment. Therefore, 18 steers were kept on pasture and 14 steers in the feedlot. None of the steers were treated with growth promotants or ionophores.

Table 1. Composition of Grain (GN) and Grass (GS) Diets

\begin{tabular}{lll}
\hline Item, \% Dry Matter & GN & GS \\
\hline Cracked Corn & 80.0 & \\
Alfalfa hay & 5.00 & \\
Molasses & 3.00 & \\
Fat & 2.50 & \\
Sodium bicarbonate & 1.25 & \\
Urea & 1.00 & \\
Oyster shell & 0.50 & \\
Trace mineral salt & 0.50 & \\
Ammonium chloride & 0.25 & \\
Potassium chloride & 1.0 & \\
Dry Matter & 91.0 & 22.0 \\
Crude Protein & 9.70 & 14.3 \\
Neutral Detergent Fiber & 18.1 & 57.6 \\
Acid Detergent Fiber & 7.15 & 37.4 \\
Lignin & 2.30 & 3.60 \\
Ash & 14.0 & 11.0 \\
Metabolizable Energy (MJ/kg dry matter) & 12.8 & 10.8 \\
Net Energy Maintenance (MJ/kg dry matter) & 8.74 & 7.36 \\
Net Energy Gain (MJ/kg dry matter) & 6.31 & 2.55 \\
\hline
\end{tabular}

GN steers were fed a finishing ration of $80 \%$ cracked corn on a DM basis (Table 1). GS steers grazed for 10 mo on average (range from 5 to $18 \mathrm{mo}$ ) on irrigated pasture of ryegrass (Lolium multiflorum) and white clover (Trifolium repens). Dietary metabolizable energy values were calculated using the NRC Nutrient Requirements of Beef Cattle (1996) equations. Ultrasound measurements were taken using a SONOVET 2000 (Universal Medical Systems Inc., Bedford Hills, NY) 81 with a $3.5-\mathrm{MHz} 17-\mathrm{cm}$ linear array transducer to assess intramuscular fat content of the Longissimus dorsi muscle (LM) between the $12^{\text {th }}$ and $13^{\text {th }}$ rib. Slaughter point was reached when steers achieved a minimum of $3.1 \%$ intramuscular fat assessed using ultrasound.

\subsection{Sample Collection}

Four distinct regions were sampled: BF over the $9-11^{\text {th }}$ rib, KPH, IMF and TF. Twenty four hours after slaughter, $\mathrm{BF}, \mathrm{KPH}$, and TF samples were collected from chilled carcasses. Two weeks post-slaughter, IMF samples were collected at the $9-11^{\text {th }}$ rib regions of the right side of the carcasses. Samples were placed in polyethylene plastic bags and stored at $-80{ }^{\circ} \mathrm{C}$ for fatty acid extraction and gas chromatography analysis of fatty acid methyl esters (FAME).

\subsection{Fatty Acid Analysis}

Fat was extracted according to Erickson and Dunkley (1964) and prepared according to Crocker et al. (1998) 
with modifications as follows. Using glass graduated pipets, $20 \mathrm{mg}$ of the extracted fat was aliquoted into a Teflon-lined, screw-cap glass culture tube. The solvent was evaporated under a stream of nitrogen at $60{ }^{\circ} \mathrm{C}$ followed by a $1.0 \mathrm{ml}$ wash of isooctane $(2,2,4$ trimethylpentane), which was also evaporated under nitrogen at $60{ }^{\circ} \mathrm{C}$. A $2.0-\mathrm{ml}$ aliquot of isooctane was added to the culture tube and vortex. FAME were formed by the addition of $100 \mu \mathrm{l}$ of $3 \mathrm{M}$ potassium hydroxide, vortex, and allowed to stand at room temperature for $10 \mathrm{~min}$. Esters were washed and separated by the addition of $2.0 \mathrm{ml}$ of saturated $\mathrm{NaCl}$ and $8.5 \mathrm{ml}$ of deionized water. Tubes were shaken with a Burell wrist action shaker for $10 \mathrm{~min}$, centrifuged at $1500 \mathrm{rpm}$ for $5 \mathrm{~min}$ to separate the methyl esters in the upper solvent layer and then aliquoted into 2.0 -ml gas chromatography auto sampler vials. Restek ${ }^{\circledR}$ FAME standards (C6:0 to $\mathrm{C} 24: 1$ cis 15$)$ were used for identification of individual fat depot's FAMEs. The ester mixture was analyzed using two stainless steel capillary columns, a Restek MXT ${ }^{\circledR}$ Wax $15 \mathrm{~m}$, $0.53 \mathrm{mmID}, 0.5 \mu \mathrm{mdf}$ and a Restek $\mathrm{MXT}^{\circledR}-500$ SimDist $15 \mathrm{~m}, 0.53 \mathrm{mmID}, 0.15 \mu \mathrm{m}$ df. Helium was used as the carrier gas with a linear flow rate set at $27 \mathrm{~cm} / \mathrm{s}$ with a column head pressure of 33 psi. A SRI 8310C gas chromatograph equipped with an EST Cobra auto-injector injected $1.0 \mu \mathrm{L}$ of sample. Injector and detector temperatures were set at $260{ }^{\circ} \mathrm{C}$, and the column temperature was programmed at $80{ }^{\circ} \mathrm{C}$ for 2 min and then increased to $200{ }^{\circ} \mathrm{C}$ at a rate of $3{ }^{\circ} \mathrm{C} / \mathrm{min}$. A flame-ionization detector with a signal range of one was used. Peak areas and heights of methyl esters were quantified and integrated using the Peaksimple Data System (SRI, Los Angeles, CA). All samples were run in duplicate and samples that deviated 5\% from each other were repeated. A C17:0 fatty acid was used as control for recovery percentage. Therefore each unknown sample received an aliquot of $\mathrm{C} 17: 0$ as an internal standard which was also used to adjust for recovery percentage.

\subsection{Statistical Analysis}

Statistical analyses were performed using R Project for Statistical Computing (version 2.12.1). Similar to Turk and Smith (2009), fatty acid composition was analyzed using ANOVA, with diet (GS or GN) and fat depot (BF, IMF, KPH, or TF) as fixed effects and final body weight (BW) as a covariate. Interaction between diet and depot was tested and if significant $(P<0.05)$ was included in the model. Percentages of each fatty acid were analyzed using the following model:

$$
Y_{i j}=\mu+\alpha_{i}+\beta_{j}+\alpha_{i} \beta_{j}+\varepsilon_{i j}
$$

where $Y_{\mathrm{ij}}$ is the percentage of each fatty acid, $\mu$ is the overall mean, $\alpha_{\mathrm{i}}$ is the effect of diet (i=1 (GN),2(GS)), $\beta_{\mathrm{j}}$ is the effect of fat depot $(\mathrm{j}=1(\mathrm{BF}), 2(\mathrm{IMF}), 3(\mathrm{KPH}), 4(\mathrm{TF})), \alpha_{\mathrm{i}} \beta_{\mathrm{j}}$ is the interaction between diets and fat depot and $\varepsilon_{\mathrm{ij}}$ are residuals which followed a normal distribution $\mathrm{N}\left(0, \sigma^{2}\right)$.

\section{Results and Discussion}

\subsection{Performance}

In the beginning of this experiment, there were no differences between GS or GN steers.

Table 2. Effect of grain (GN) or grass (GS) diets in finishing steers on performance and ultrasound data

\begin{tabular}{lllll}
\hline & GN & GS & SEM & $P$ - value \\
\hline Number of Steers & 14 & 18 & & \\
Initial Body Weight, kg & 416 & 407 & 6.0 & 0.5 \\
Final Body Weight, kg & 641 & 615 & 7.2 & $<0.001$ \\
Average Total Gain, kg & 226 & 208 & 7.4 & 0.1 \\
Average Daily Gain, kg/d & 1.3 & 0.76 & 0.03 & $<0.001$ \\
Average days on feed, d & 168 & 303 & 10 & $<0.001$ \\
Initial Longissimus dorsi area, Ultrasound cm ${ }^{2}$ & 61.5 & 60.0 & 0.99 & 0.5 \\
Final Longissimus dorsi area, Ultrasound cm ${ }^{2}$ & 83.6 & 79.4 & 1.4 & 0.2 \\
Initial Intermuscular Fat, Ultrasound \% & 1.33 & 1.32 & 0.090 & 0.9 \\
Final Intermuscular Fat, Ultrasound \% & 4.76 & 3.39 & 0.11 & $<0.001$ \\
Initial Back Fat, Ultrasound cm & 0.44 & 0.47 & 0.03 & 0.6 \\
Final Back Fat, Ultrasound cm & 1.2 & 0.79 & 0.04 & $<0.001$ \\
Initial Rump Fat, Ultrasound cm & 0.59 & 0.59 & 0.04 & 0.9 \\
Final Rump Fat, Ultrasound cm & 1.4 & 1.1 & 0.05 & 0.01 \\
\hline
\end{tabular}


As shown in Table 2, steers began the study at similar initial BW and initial ultrasound measurements: LM area, rump fat (RF) and BF. GN steers gained weight faster than GS steers and therefore required fewer days on feed (168 vs. 303 d, respectively, $P<0.001$ ). GN steers were also heavier at the end of the study, with a final BW of 641 vs. $615 \mathrm{~kg}(P<0.001)$. There is considerable variability in ultrasound measurements (Houghton \& Turlington, 1992). Due to the difficulty in obtaining consistent intramuscular fat percentage measurements, some steers were fatter at slaughter. Therefore GN had a significantly greater IMF, BF and RF content than GS at harvest.

Evaluation of carcass composition was performed using dissection of the $9-11^{\text {th }}$ rib (Hankins and Howe, 1946). Carcasses from GS steers were composed of $60.7 \%$ muscle, $21.2 \%$ fat and $15.4 \%$ bone and GN carcasses were composed of $56.4 \%$ muscle, $25.5 \%$ fat and $14.0 \%$ bone. Therefore, carcasses from GS had relatively more muscle and less fat $(P<0.001)$ compared to GN steers.

3.2 Changes in Saturated Fatty Acids (SFA)

Table 3. Effect of grain (GN) or grass (GS) diets on fatty acid composition of backfat (BF), intermuscular fat (IMF), Kidney pelvis heart fat (KPH) and tail fat (TF)

\begin{tabular}{|c|c|c|c|c|c|c|c|c|c|c|c|c|}
\hline \multirow[b]{2}{*}{ Fatty acid, \% } & \multicolumn{4}{|c|}{ GN } & \multicolumn{4}{|c|}{ GS } & \multicolumn{2}{|c|}{ Treatment } & \multicolumn{2}{|c|}{ Depot } \\
\hline & $\mathrm{BF}$ & IMF & $\mathrm{KPH}$ & $\mathrm{TF}$ & $\mathrm{BF}$ & IMF & KPH & $\mathrm{TF}$ & SEM & $P$-value & SEM & $P$-value \\
\hline $6: 0$ & 1.34 & 1.22 & 1.24 & 1.43 & 2.61 & 2.11 & 2.39 & 3.00 & 0.16 & 0.008 & 0.19 & 0.9 \\
\hline 10:0 & 1.99 & 1.59 & 1.68 & 1.56 & 1.24 & 1.43 & 1.91 & 1.60 & 0.17 & 0.4 & 0.17 & 0.6 \\
\hline 11:0 & 0.51 & 0.54 & 0.51 & 0.81 & 0.83 & 0.86 & 0.99 & 0.86 & 0.11 & 0.03 & 0.11 & 0.9 \\
\hline 12:0 & 0.71 & 0.76 & 0.73 & 0.70 & 0.86 & 0.94 & 0.97 & 1.17 & 0.08 & 0.003 & 0.08 & 0.6 \\
\hline 14:0 & 2.28 & 2.35 & 2.65 & 2.34 & 3.84 & 3.61 & 4.28 & 3.83 & 0.44 & 0.001 & 0.46 & 0.9 \\
\hline $14: 1$ & 1.65 & 1.58 & 1.24 & 1.98 & 2.13 & 2.14 & 2.06 & 2.39 & 0.23 & 0.02 & 0.23 & 0.5 \\
\hline 16:0 & 10.30 & 10.10 & 12.80 & 10.20 & 18.70 & 18.50 & 21.50 & 17.70 & 2.50 & 0.002 & 2.60 & 0.8 \\
\hline $16: 1$ & 4.04 & 5.35 & 6.06 & 3.76 & 4.21 & 4.36 & 4.30 & 3.75 & 0.38 & 0.1 & 0.38 & 0.08 \\
\hline 18:0 & 20.40 & 22.50 & 25.50 & 19.72 & 14.40 & 17.60 & 17.40 & 12.30 & 1.20 & $<0.001$ & 1.30 & 0.02 \\
\hline$c 9,18: 1$ & 52.60 & 40.40 & 28.80 & 54.01 & 41.20 & 39.60 & 30.60 & 44.70 & 3.40 & 0.2 & 3.20 & $<0.001$ \\
\hline$c 9, c 1218: 2$ & 1.38 & 1.31 & 1.25 & 1.41 & 1.98 & 1.98 & 2.21 & 2.34 & 0.14 & $<0.001$ & 0.15 & 0.6 \\
\hline$t 9,18: 1$ & 2.18 & 2.03 & 2.51 & 2.08 & 3.65 & 3.75 & 3.90 & 3.84 & 0.52 & 0.004 & 0.55 & 0.9 \\
\hline$t 9, t 12,18: 2$ & 0.14 & 0.13 & 0.18 & 0.13 & 0.43 & 0.46 & 0.32 & 0.36 & 0.03 & $<0.001$ & 0.04 & 0.9 \\
\hline $18: 3$ & 0.54 & 0.51 & 0.45 & 0.44 & 0.93 & 1.08 & 1.15 & 0.81 & 0.09 & 0.008 & 0.10 & 0.8 \\
\hline 20:0 & 0.23 & 0.23 & 0.16 & 0.16 & 0.41 & 0.44 & 0.41 & 0.40 & 0.05 & $<0.001$ & 0.06 & 0.9 \\
\hline$c 5,20: 1$ & 0.25 & 0.20 & 0.13 & 0.16 & 0.22 & 0.21 & 0.17 & 0.21 & 0.02 & 0.7 & 0.02 & 0.3 \\
\hline$c 11,20: 1$ & 0.11 & 0.08 & 0.11 & 0.12 & 0.53 & 0.21 & 0.19 & 0.20 & 0.10 & 0.2 & 0.19 & 0.3 \\
\hline $20: 2$ & 0.27 & 0.28 & 0.25 & 0.20 & 0.19 & 0.24 & 0.23 & 0.20 & 0.04 & 0.4 & 0.04 & 0.8 \\
\hline $22: 0$ & 0.060 & 0.01 & 0.03 & 0.16 & 0.08 & 0.10 & 0.07 & 0.12 & 0.01 & 0.2 & 0.01 & 0.1 \\
\hline$c 13,22: 1$ & 0.35 & 0.05 & 0.05 & & 0.23 & 0.11 & 0.09 & 0.11 & 0.03 & 0.4 & 0.03 & 0.09 \\
\hline $22: 2$ & 0.05 & 0.04 & 0.08 & & 0.25 & 0.13 & 0.15 & 0.09 & 0.02 & 0.2 & 0.02 & 0.5 \\
\hline 24:0 & 0.01 & 0.17 & 0.02 & 0.03 & 0.02 & 0.02 & 0.03 & 0.02 & 0.01 & $<0.001$ & 0.01 & $<0.001$ \\
\hline$c 15,24: 1$ & 0.04 & 0.15 & 0.09 & 0.05 & 0.72 & 0.06 & 0.20 & 0.12 & 0.02 & 0.5 & 0.02 & 0.6 \\
\hline Total SFA & 37.8 & 39.5 & 45.3 & 37.1 & 43.0 & 45.5 & 50.0 & 41.1 & 0.58 & 0.1 & 0.45 & 0.2 \\
\hline Total USFA & 65.4 & 53.7 & 42.9 & 65.7 & 56.6 & 54.6 & 44.4 & 58.3 & 2.9 & 0.4 & 2.4 & 0.5 \\
\hline
\end{tabular}

Means Expressed as Relative Weight Percentages (g Fatty Acid/100g Fatty Acid). Treatment is comparison of grass and grain-finished steers. Depot is comparison of backfat, intermuscular fat, kidney pelvis heart fat and tail fat depots. SFA= saturated fatty acid; USFA= unsaturated fatty acid.

Fatty acid percentages by diet and fat depot are listed in Table 3. Fat depots from GS contained higher percentages of saturated fatty acids (SFA) such as C6:0 $(P=0.008), \mathrm{C} 11: 0(P=0.03), \mathrm{C} 12: 0(P=0.003), \mathrm{C} 14: 0$ 
$(P=0.001), \mathrm{C} 16: 0(P=0.002), \mathrm{C} 20: 0(P<0.001)$ and $\mathrm{C} 24: 0(P<0.001)$ than $\mathrm{GN}$ steers. But GN steers fat depots had higher percentages of C18:0 $(P<0.001)$. There was no difference in percentage of C10:0 $(P=0.400)$, C22:0 and total SFA $(P=0.11)$ between GN and GS carcasses. These findings are in agreement with those of Leheska et al. (2008) who compared fatty acid composition of ground beef and strip steaks of grass fed and conventionally fed beef. They concluded that SFA, such as C8:0, C10:0, C12:0, C14:0, C15:0, C16:0, C17:0, $\mathrm{C} 18: 0$ and C20:0 content of grass fed was greater than that of conventionally fed steers. French et al. (2000) also evaluated the effects of feeding grass, grass silage and concentrate on the fatty acid composition of IMF of 50 steers and concluded that decreasing concentrates and increasing grass in the diets resulted in a decrease in the percentage of SFA in KPH fat. Turk and Smith (2009) postulated that higher percentages of SFA were found in the flank compared to the other fat depots due to greater accumulation of C18:0 fatty acids and low activity of $\Delta^{9}$ desaturase enzyme. Data from the current study also shows that greater percentages of SFA in GS steers resulted primarily from the greater concentration of stearic acid (C18:0), C14:0 and C16:0. Among the SFA, C14:0 and C16:0 have been shown to have the greatest impact on raising serum cholesterol levels (Ahrens et al., 1957; Keys et al., 1965). Thus, both diet and depot impact SFA composition of fat depots.

\subsection{Changes in Unsaturated Fatty Acids (USFA)}

The percentage of C14:1 in the adipose tissue of GS steers was higher than that in GN steers $(P=0.016)$. But percentages of C16:1, C18:1, C20:1 cis5, C20:1 cis 11, C20:2, C22:1, C22:2 and C24:1 did not differ for steers finished on GN or GS. GN steers had higher percentages of total unsaturated fatty acids $(P=0.418)$ when compared with GS steers. However, GS steers had higher percentages of C18:2 cis 9 cis $12(P<0.001)$. Fat from GN steers has been consistently shown to produce higher concentrations of total mono-unsaturated fatty acids (MUFA) compared to GS steers, especially C18:1cis 9 but a lower content of n-3 fatty acids, C18:2 n-6 fatty acids and trans-vaccenic acid (Leheska et al., 2008). French et al. (2000) also confirmed that the concentration of polyunsaturated fatty acids (PUFA) was higher for steers fed concentrates. Similar results were found in the present study; GS steers exhibited lower percentages of MUFA compared with GN steers $(P=0.002)$. MUFA have been correlated with positive health benefits such as control of diabetes and an increase in insulin sensitivity (Groff \& Groper, 1999) and usually comprise half of the beef fat. In this study, the highest concentration of MUFA was oleic acid (C18:1n-9) and oleic acid was greater in GN steers. MUFA percentages were not different between GN and GS steers $(P=0.160)$. The percentages of $\mathrm{C} 18: 1$ trans $9(P=0.004), \mathrm{C} 18: 2$ cis 9 cis $12(P<0.001), \mathrm{C} 18: 2$ trans 9 trans $12(P<0.001)$ and $\mathrm{C} 18: 3(P=0.008)$ were higher for GS than GN steers.

Fatty acid composition is affected by diet. Higher percentages of C18:2 cis 9 cis 12 is present in fat from cattle finished on grain diets (Daley et al., 2010). In this study, GS steers produced fat with higher percentages of C18:2 cis 9 cis 12 which is directly associated with the fatty acid composition of the ryegrass (Lolium multiflorum) and white clover (Trifolium repens) grazed during the experimental period. Elgersma, 2003 also found that the fatty acid composition of forages (fresh and ensiled ryegrass) impacted the percentage of C18:2 cis 9 cis 12 which was $10.2 \%$ of the total fatty acid of fresh ryegrass. Dalmannsdóttir et al. (2001) analyzed the fatty acid composition of white clover in relation to frosting tolerance and concluded that white clover in temperate climate conditions (no ice or frost) had $5.25 \mathrm{mg} / \mathrm{g}$ DM of C18:2 cis 9 cis 12 in September of that year and $3.31 \mathrm{mg} / \mathrm{g}$ dry matter in January of the same year. In this study, GS steers grazing a mixed pasture composed by ryegrass and white clover also had fat depots with higher percentages of C18:2 cis 9 cis 12 compared to GN.

\subsection{Changes in Trans Fatty Acids}

Naturally occurring trans fatty acids are found in meat and milk from ruminant animals. However, ruminant products with trans fatty acids do not show the same properties as manufactured products with trans fatty acids. Manufactured trans-fat products have been correlated with increase in risk of heart disease (Lopez-Garcia et al., 2005). Trans isomers of C18:1 are used as substrates for de novo synthesis of C18:2 n-6 fatty, an omega-6 fatty acid. In this study, the highest percentage of trans fat in GS consisted of C18:1 t9. Greater percentages of C18:2 $c 9 c 12$ and $\mathrm{C} 18: 2$ t9 t12 were found in GS when compared to GN steers. Also, C18:2 n-6 content was 1.6 times greater for the GS group compared to GN. This result is in agreement with French et al. (2000) and Noci et al. (2005) who observed that regardless the fat depot, content of C18:2 n-6 of GS was approximately 2 times greater than GN fat content.

The typical American diet, with low fish intake and high margarine and vegetable oil intake, leads to a higher $\mathrm{n}-6$ to n-3 ratio (i.e. 11 to 30 times more $n-6$ fatty acids than n-3 fatty acids). The higher intake of n- 6 to $n-3$ has been suggested to be a major contributor to rising rates of cardiovascular disease, elevated cholesterol levels and increased inflammatory disorders in the USA (Simopoulos, 1991; Makrides et al., 1995). Appropriate ratios of 
n-6 to n-3 fatty acids may decrease risk of heart disease. Fatty acid composition can be changed with diet to assure more desirable ratios. In the present study, the ratios of n- 6 to $n-3$ are 1.9 and 0.63 for GS and GN steers, respectively. Consumption of fat from milk and meat instead of manufactured fat, such as margarine and vegetable oils, can promote a healthier balance of the ratio n- 6 and n-3 fatty acids. Beef products from cattle finished on a grass based diet can also benefit consumers due to its high concentration of omega-3 fatty acids which can decrease incidence of cardiovascular disease. In light of these beneficial properties of ruminant products, retailers can manipulate fat depots in processed beef to promote healthier beef products.

\subsection{Changes in Fatty Acid Profile Due to Diet and Fat Depot}

The only fatty acid that was statistically significant among fat depots by diet was C24:0 which was higher in IMF of GS $(P<0.001)$ and higher in KPH of GN steers $(P<0.001)$. In general the highest content of SFA in internal fat depots (IMF and KPH) are associated with extensive action of $\Delta^{9}$ desaturase enzymes in internal fat depots compared to outer fat depots for medium and long chain fatty acids (Turk \& Smith, 2009).

\subsection{Changes in Fatty Acid Profile Due to Depot}

Hansen et al. (1952) and Sink et al. (1964) reported percentages of odd-chain and branched chain fatty acids among fat depots were very low. Our results agree and so were excluded from the total fatty acid analysis. However, C11:0 was higher in GS than GN steers. The sum of the other odd-chain fatty acids comprised only $2.0 \%$ of the total fat sample.

\subsection{Changes in Fatty Acid Composition between Inner Fat Depots (IMF and KPH) and Outer Fat Depots (BF and $T F)$}

For inner fat depots, IMF of GN had higher percentages of C18:0 $(P=0.015)$ and C24:0 $(P<0.001)$ compared to GS steers. The percentages of C11:0, C14:1, C18:2 cis 9 cis 12 and C20:0 in KPH fat depots were greater for GS steers than for GN steers $(P=0.029, P=0.016, P<0.001$ and $P<0.001$, respectively). However, the percentage of C18:0 was significantly greater for GN steers $(P<0.001)$ in KPH. Ostrander \& Dugan (1962) compared fatty acid composition of BF, KPH and IMF and concluded that KPH contained a greater percentage of C18:0. In addition percentages of C18:1 were lower in KPH and IMF compared to BF and TF $(P<0.050)$. These results are similar to the current study in which the greatest content of C18:0 was also associated with double bond saturation of C18:1 by $\Delta^{9}$ desaturase enzyme present in KPH and IMF fat depots (Turk \& Smith, 2009). Waldman et al. (1968) compared fatty acid composition of 22 Angus steers and 18 Angus heifers on the same diet at a weight of 386, 420 or $454 \mathrm{~kg}$ and concluded that IMF exhibited more SFA than BF, primarily due to replacement of oleic acid (C18:1) by stearic acid (C18:0) and to a decrease in the levels of palmitoleic acid (C16:1) in KPH fat depots.

$\mathrm{BF}$ and TF depots were not different in percentage of SFA compared to KPH and IMF depots $(P=0.226)$. There was not a difference in percent palmitoleic acid in KPH and IMF depots compared to BF and TF depots which implied there was no difference in SFA between fat depots $(P=0.083)$.

Comparison between GN and GS steers revealed that when all four fat depots, BF, IMF, KPH and TF were combined, percentages of C18:0 were higher for GN. GS steers had higher percentages of C18:2 cis 9 cis 12 , $\mathrm{C} 18: 3$ and $\mathrm{C} 20: 0$ regardless of fat depot. Higher percentages of $\mathrm{C} 18: 2$ cis 9 cis 12, C18:3 and C20:0 is associated with high rates of desaturation and higher percentages of C18:2 in ryegrass (Lolium multiflorum) and white clover (Trifolium repens). Therefore finishing beef cattle on grass produced carcasses with higher percentages of SFA and C18:2 n-6 compared to GN steers. Fatty acid profiles were different among fat depots; KPH had a higher content of $\mathrm{C} 18: 0$ and lower content of $\mathrm{C} 18: 1$ compared to the other fat depots. In ruminants, fatty acid deposition follows a non-simultaneous pattern being first deposited into visceral fat (KPH), followed by deposition into subcutaneous and IMF. In this study, percentage of total SFA was lower in adipose of GN than GS steers and fat depot sites of GN steers had higher concentrations of MUFA than GS. Also, higher concentrations of PUFA were found in GN steers than GS steers. Regardless of fat depot, GN steers showed higher percentages of MUFA, lower percentages of SFA and higher percentages of C18:0. GS steers showed higher percentages of $\mathrm{C} 18: 3$ and $\mathrm{C} 18: 2$ cis 9 cis 12 , an important fatty acid that has beneficial health effects including lowering cholesterol levels and reducing the risk of heart disease.

\section{Conclusions}

This study demonstrates that fatty acid composition differs among diets and fat depots. The pattern of distribution of fatty acids are not static confirming that GS beef is potentially healthier than beef from GN steers and could be adapted to modify the fatty acid composition of processed beef products by mixing fat from GS with lean from GN. Therefore fatty acid composition can be affected by both depots and diet. 


\section{References}

Ahrens, E. H. Hirsch, Jr., J., Insull, W., Tsaltas, T. T., Blomstrand, R., \& Peterson, M. L. (1957). The influence of dietary fats on serum-lipid levels in man. Lancet, 272, 943-953. http://dx.doi.org/10.1016/S0140-6736(57)91280-1

Crocker, L. M., DePeters, E. J., Fadel, J. G, Perez-Monti, H., Taylor, S. J., Wyckoff, J. A., \& Zinn, R. A. (1998). Influence of processed corn grain in diets of dairy cows on digestion of nutrients and milk composition. Journal of Dairy Science, 81, 2394-2407. http://dx.doi.org/10.3168/jds.S0022-0302(98)70131-6

Daley, A. C., Abbott, A., Doyle, P. S., Nader, G. A., \& Larson, S. (2010). A Review of Fatty Acid Profiles and Antioxidant Content in Grass-Fed and Grain-Fed Beef. Nutrition Journal, 9, 1-12. http://dx.doi.org/10.1186/1475-2891-9-10

Dalmannsdóttir, S., Helgadóttir, A., \& Gudleifsson, B. E. (2001). Fatty acid and sugar content in white clover in relation to frost tolerance and ice-encasement tolerance. Annals of Botany, 88, 753-759 http://dx.doi.org/10.1093/aob/mcn159

Elgersma, A. (2003). Comparison of the fatty acid composition of fresh and ensiled perennial ryegrass (Lolium perenne L.), affected by cultivar and regrowth interval. Animal Feed Science and Technology, 108, 191-205. http://dx.doi.org/10.1016/S0377-8401(03)00134-2

Erickson, D. R., \& Dunkley, W. L. (1964). Spectrophotometric determination of tocopherol in milk and milk lipids. Analytical Chemistry, 36, 1055-1058. http://dx.doi.org/10.1021/ac60212a029

Frayn, K. N., Arner, P., \& Yki-Jarvinen, H. (2006). Fatty acid metabolism in adipose tissue, muscle and liver in health and disease. Essays Biochem, 42, 89-103.

French, P., Stanton, C., Lawless, F., Riordan, E. G. O'., Monahan, F. J., Caffery, P. J., \& Moloney, A. P. (2000). Fatty acid composition, including conjugated linoleic acid of intramuscular fat from steers offered grazed grass, grass silage or concentrate-based diets. Journal of Animal Science 78, 2849-55.

Groff, J. L., \& Gropper, S. S. (1999). Advanced Nutrition and Human Metabolism. Wadsworth Publishing Co, Belmont CA.

Hankins, O. G., \& Howe, P. E. (1946). Estimation of the composition of beef carcasses and cuts. United States Department of Agriculture Technical bulletin No. 926, 1-20.

Hansen, R. P., \& Shorland, F. B. (1952). The branched-chain fatty acids of butterfat. 2. The isolation of a multi-branched $\mathrm{C}_{20}$ saturated fatty acid fraction. Biochem Journal, $50,358$.

Houghton, P. L., \& Turlington, L. M. (1992). Application of ultrasound for feeding and finishing animals: A Review. Journal of Animal Science, 70, 930-94.

Keys, A., Anderson, J. T., \& Grande, F. (1965). Serum cholesterol response to changes in the diet. IV. Particular saturated fatty acids in the diet. Metabolism, 14, 776-787. http://dx.doi.org/10.1016/0026-0495(65)90001-6

Leheska, J. M., Thompson, L. D., Howe, J. C., Hentges, Boyce, E., Brooks, J. J. C., ... Miller, M. F. (2008). Effects of conventional and grass-feeding systems on the nutrient composition of beef. Journal of Animal Science, 86, 3575-85. http://dx.doi.org/10.2527/jas.2007-0565

Lopez-Garcia, E., Schulze, M. B., Meigs, J. B., Manson, J. E., Rifai, N., \& Stampfer, M. J. (2005). Consumption of trans fatty acids is related to plasma biomarkers of inflammation and endothelial dysfunction. Journal of Nutrition, 135, 562-566.

Makrides, M., Neumann, M., Simmer, K., Pater, J., \& Gibson, R. (1995). Are long-chain polyunsaturated fatty acids essential nutrients in infancy? Lancet, 345 , 1468. http://dx.doi.org/10.1016/S0140-6736(95)91035-2

NRC (National Research Council). (1996). Assessment Using Food Consumption Surveys. National Academy Press, Washington, DC.

Noci, F., O'Kiely, P., Monahan, F. J., Stanton, C., \& Moloney, A. P. (2005). Conjugated linoleic acid concentration in M. Longissimus dorsi from heifers offered sunflower oil-based concentrates and conserved forages. Meat Science, 69, 509-518. http://dx.doi.org/10.1016/j.meatsci.2004.09.006

Ostrander, J., \& Dugan, L. R. Jr (1962). Some differences in composition of covering fat, intermuscular fat and intramuscular fat of meat animals. Journal of American Oil Chemistry Society, 39, $178-181$. http://dx.doi.org/10.1007/BF02632758 
Pethick, D. W., Harper, G. S., \& Oddy, V. H. (2004). Growth, development and nutritional manipulation of marbling in cattle: A review. Australian Journal of Experimental Agriculture, 44, 705-715. http://dx.doi.org/10.1071/EA02165

Simopoulos, A. (1991). Omega-3 fatty acids in health and disease and in growth and development. American Journal of Clinical Nutrition, 54, 438-63.

Sink, J. D., Watkins, J. L., Ziegler, J. H., \& Miller, R. C. (1964). Analysis of fat deposition in swine by gas-liquid chromatography. Journal of Animal Science, 23, 121-125.

Turk, S. N., \& Smith, S. B. (2009). Carcass fatty acid mapping. Meat Science, 81, 658-663. http://dx.doi.org/10.1016/j.meatsci.2008.11.005

USDA. (1996). Standards for Grades of Slaughter and Standards for Grades of Carcass Beef. AMS, USDA, Washington, D. C.

Waldman, R. C., Suess, G. G., \& Brungardt, V. H. (1968). Fatty acids of certain bovine tissue and their association with growth, carcass and palatability traits. Journal of Animal Science, 27, 632-635.

\section{Copyrights}

Copyright for this article is retained by the author(s), with first publication rights granted to the journal.

This is an open-access article distributed under the terms and conditions of the Creative Commons Attribution license (http://creativecommons.org/licenses/by/3.0/). 